\title{
Assessing Final-Year Practical Work Through Group Projects; A Further Study
}

\author{
Philippa B. Cranwell* \& Elizabeth M. Page
}

Department of Chemistry, University of Reading, Whiteknights Campus, RG6 6AD

Corresponding author: p.b.cranwell@reading.ac.uk

Keywords: Group working; Problem based learning; Collaborative learning; Student led research; Final year project

\begin{abstract}
The use of a group-based approach to project working has been shown to provide significant advantage to students in terms of project outcomes, motivation and engagement. The Department of Chemistry at the University of Reading has recently explored the use of group projects for final year practical work. In this model, students are presented with a research problem that they investigate within a team of three to five students. Students are expected to divide the work and share results in a manner that closely resembles project working in industry. This paper will report the experiences and attitudes of final-year BSc students towards this group-based approach, and outline the self-identified skills development of these students.
\end{abstract}

\section{Background}

The prevalence of using small groups as a teaching-aid in higher education has increased over recent years and small-group work is an important element of active learning theory and practice (Burke, 2011). This has occurred, in part, due to increasing class sizes, but it had also been shown that the use of small group teaching leads to students out-performing their counterparts in a number of key areas including knowledge development, thinking skills, social skills and course satisfaction (Davidson \& Major, 2014). A myriad of publications has emerged that discuss the different approaches to small-group teaching, with specific names given to differentiate the varying approaches including small-group learning, collaborative learning, cooperative learning, problem-based learning (PBL) teambased learning, peer instruction, peer tutoring and team learning (Davidson \& Major, 2014). Each of these approaches has a slightly different ethos, with different ways of running the project and differing expectations upon the students and the instructor. However, the sheer number of options available can be daunting and may serve as a barrier when choosing to follow a group-based learning approach. Over recent years three main themes have emerged: cooperative learning, collaborative learning and problem-based learning (PBL). All three have uses in different situations depending upon the desired student outcome. It should be noted cooperative learning is often used in the sciences and STEM subjects, collaborative learning is used in the humanities, and problem-based learning has been used extensively in the health professions (Davidson and Major, 2014).

Cooperative learning is defined as "students working together in a group small enough that everyone can participate on a collective task that has been clearly assigned. Moreover, students are expected to carry out their task without direct and immediate supervision of the teacher" (Cohen, 1994, p. 3). The main feature of cooperative learning is that students work together towards a common goal, with minimal supervision from the instructor. Students may have different tasks within a team, therefore the project should contain elements that 
involve individual effort (Davidson \& Worsham, 1992). Davidson and Worsham (1992) suggest that there are four critical criteria for a successful cooperative learning task: (1) the task or learning activity must be suitable for group work; (2) student-to-student interaction in small groups must be facilitated; (3) interdependence between students is structured to foster cooperation in small groups; and (4) there must be individual responsibility and accountability. In later work, Davidson (1992, 2004) added a fifth criterion: there should be cooperative and mutually helpful behaviour amongst students. Extensive meta-analysis by Springer, Stanne and Donovan (1999) has shown core differences between STEM undergraduate students working in a cooperative learning environment compared to those who have not. Firstly, students working in a cooperative learning environment performed better than counterparts; secondly, these students are more likely to continue further study within STEM subjects compared to their counterparts; and thirdly these students tended to have a more favourable attitude towards the STEM topics than their counterparts.

Collaborative learning is when "students and faculty work together to create knowledge" (Matthews,1996, p. 101) i.e. students work in collaboration with the instructor to reach a common goal and are required to articulate and defend their ideas (Laal \& Laal, 2012). For example, in a collaborative project, students could divide the task and assemble individual parts to accomplish the common goal with minimal interdependence. In a cooperative project, all members would be held accountable to increase their knowledge of the individual parts (Davidson \& Major, 2014). Within a collaborative learning project, the learning responsibility still resides with the students and when addressing the research question each student may have a different task that builds towards reaching the common goal. Forrestal (in Brubacher et al., 1990) states that the five stages of collaborative learning are:

- Engagement - students meet and engage with information about the question or project, for example by reading papers or attending a lecture.
- Exploration - students make an initial exploration of the information and link past experience with any new information that they have been given.

- Transformation - students work with the information to understand it. The instructor can become involved at this stage and may address misconceptions or provide additional information.

- Presentation - students present their findings to a critical audience.

- Reflection - students look back at what they have learnt to gain a deeper understanding of the content and learning process they have just completed.

Collaborative learning has not been as widely researched as cooperative learning, but numerous positive outcomes have been cited. For example, Cabrera et al. (2002) found positive outcomes in relation to student attainment and openness to diversity and Tinto, Goodsell and Russo (1993) found positive effects on student engagement.

Problem-based learning ( $\mathrm{PBL}$ ) is where the problem provides the learning and there can be more than one answer (Davidson \& Major, 2014; Major \& Eck, 2000). As stated earlier, PBL has been widely adopted by the medical profession and relies upon students working with complex, real-world problems. It has been suggested that PBL addresses many of the desirable outcomes from an undergraduate education including critical thinking, evaluation, cooperative working, versatile communication skills and using research skills to become a continual learner (Boud \& Feletti, 1997, p. 2). Barrows (1986) identifies the nine essential characteristics of a PBL task as:

- Problem-based, to address a real-world issue

- Interdisciplinary

- Authentic

- Motivating

- Student-centred

- Self-directed

- Skill-directed

- Collaborative

- Reflective 
The different approaches to group-work outlined above have their advantages and disadvantages, but all have been shown to have a positive effect upon student attainment, engagement and skills development. For a further in-depth discussion of these three approaches, Davidson and Major (2014) provide an excellent review.

\section{Project work during the final year of a BSc Chemistry programme}

The final-year project within a BSc degree programme is often seen as a capstone, where students are able to bring together the knowledge and practical skills developed over their preceding two years of study. During an in-depth review of our degree programme, we realised that the individual research project BSc students completed at the end of their studies was often compromised by students' lack of self-confidence and the limited time in which to collect meaningful and sufficient data; students were not fulfilling their potential. For the reasons outlined above, we believed that the pedagogic advantages, particularly relating to skills development, offered by utilising a group-based project would offer significant benefit to our students. This decision led us to alter the delivery of our final-year research projects to BSc students (Cranwell et al., 2017).

At the start of the project, students were asked to select their preferred area of chemistry (organic, inorganic, physical, analytical) in which to focus the project and they were then grouped thematically under these subdivisions. The projects themselves were not strictly designed such that they were collaborative, cooperative or PBL, and were usually a blend of the three approaches.

Two examples of research projects are outlined below and show two slightly different approaches relating to the freedom that students could have when answering the research question. In 2016/17 one inorganic project related to the development of transition metal complexes that could undergo photooxidation in order to photocleave DNA. In this project, each student had to prepare a different Co(II) complex that could be oxidised, and fully characterise the starting material and products. Students had to work with the academic member of staff and their team-mates to deduce which complex was the most suitable for combination with DNA, and also had to combine knowledge derived by other team members to answer the question. In this case the research question was pre-defined by the academic member of staff. However, in the project example designated as analytical, students were tasked with deducing the mechanism of the Finkelstein reaction using ${ }^{1} \mathrm{H}$ NMR spectroscopy. Once students had learnt how to operate the spectrometer and interpret the results they were able to further define their own research question(s) with minimal input from the instructor, (for example if the substrate affected whether the reaction followed an $S_{N} 1$ or $S_{N} 2$ pathway; the activation energy for each pathway; the rate of reaction). Students worked together to design experiments and discuss the research within their team to answer the question(s) they proposed. This analytical project was repeated in 2017/18, although students decided to investigate different aspects. The project designed as inorganic was led by a different member of staff in $2017 / 18$ and students investigated a different research question.

Support for the students by staff was as uniform as practicable across the subdivisions over both years (2016/17 and 2017/18), with one member of academic staff leading one or two teams of students however, the nature of each project dictated how much input academic staff were required to have. The student:staff ratio ranged from four to eight students per member of staff, and students were arranged into teams of between three and five. Staff were available to directly supervise students on the days that practical aspects were timetabled (up to 18 hours over 2 days per week, autumn term), and if students required additional support it was made clear that they were able to arrange additional team meetings, but the onus was on the students to arrange these. Support was also available throughout the write-up period (spring term).

The projects available to students in 2016/17 and $2017 / 18$ did vary slightly due to staff availability, but in all cases students completed a project in their preferred research area. Where a similar project had been completed in the previous year students were aware and, if they wished, they used the previous students' work as their own starting-point. When marking 
the laboratory notebooks, final reports and oral presentations, staff expectations for the quality and volume of work the students produced were in alignment as far as possible between the two cohorts investigated and the area of chemistry (organic, inorganic, physical, analytical) that students were working within. There were no significant differences in student grade outcomes between 2016/17 and 2017/18.

Finally, to prepare students for this mode of assessment in Year 3, during Years 1 and 2 of the BSc degree programme, we ensured that students had already carried out a substantial amount of classroom-based group work and were accustomed to working within, and presenting findings as part of, a team. They had also received training on various aspects of group-work, such as group dynamics and management, group-roles and personality types, and resolving group-working issues.

\section{Project timeline and assessment}

Assessment and data collection during the projects comprised two distinct sections. All data collection and practical work was undertaken by students over a 10-week period in the autumn term. In the spring term students completed an assessed group presentation and a written report. In 2016/17, the report was written collectively by the students and a single report was submitted by the whole team. The assessment procedure was changed slightly in 2017/18 following student consultations and module evaluations. In 2017/18, each student wrote an individual report but were able to use data collected by other team members provided it was clear that this was the case. The assessment breakdown was: performance during the project and quality of laboratory notebook, $25 \%$; final project report, $50 \%$; group oral presentation, $25 \%$. The laboratory notebook was assessed by the supervisor, the project report was independently assessed by at least two members of academic staff and the oral presentation was assessed by a team of between three and four members of academic staff, ensuring that the marks allocated were as robust as possible.

\section{Research Aim}

The research aim was to report the experiences and attitudes of final-year BSc students towards group-based projects. In addition, students were invited to critically reflect and report on their skills development.

\section{Methods}

Participants in this study were enrolled on the BSc Chemistry, BSc Chemistry with a Year in Industry or BSc Chemistry with Forensics degree programmes at the University of Reading between 2015 and 2018. These are full-time programmes that are each three years in duration. Each study, completed over two academic cycles (2016/17 and 2017/18), was divided into three parts. The first phase of each study, Phase 1, was completed during October 2016 or October 2017, as students were beginning project work. All students were asked about their preconceptions of the groupbased projects using a hand-written questionnaire $(n=54)$. In this stage students were given the key information about the research project. All students signed a consent form. Ethical approval for this preliminary study was granted by the School of Chemistry, Food and Pharmacy Ethics Committee at the University of Reading.

Phase 2 of each study was undertaken in January 2017 or January 2018. Students were asked to reflect upon the practical work that they had undertaken in the group $(n=31)$. The third and final part of each study, Phase 3, was completed in March 2017 or March 2018, and required students to reflect upon the project as a whole, including the presentation and reportwriting aspects $(n=39)$. Students could not be identified through their responses. All data were collected in paper format and then transferred into Excel for thematic analysis.

\section{Outcomes}

\section{Phase 1 - Students' prior attitudes towards group-work}

In the first instance, students were asked whether they would prefer to have an individual project or a group project in their final year. Overwhelmingly, $76.5 \%$ of students were in favour of a group project. The reasons given for this were predominantly due to the fact that students had previously enjoyed group work, although they were aware of the challenges. Many students cited that by working in a team there were additional people to talk to so more 
ideas could be generated. For example, one student stated "I prefer working in a team [because I can] discuss other ideas to generate better decisions". Another strong theme was the perceived additional support provided by team members, and some students thought that completing an individual project rather than a group project would be more stressful. One student stated that an individual project would be "stressful as I didn't have high grades in Year 2". One final theme that was consistently mentioned was the development of skills vital for employment, for example the development of team-working skills and communication. When students were asked whether they thought they would be able to fully engage with a research task, despite working within a team rather than individually, the majority of students $(91.3 \%)$ thought that they would be able to undertake original research and contribute meaningfully to the scientific community.

There were, however, some negative comments surrounding group-work. The most common comments related to the perceived dependence of individual grades and project outcomes on other students' contributions.

\section{Phase 2 - Students' experiences of practical work}

Upon completion of the practical work, students' opinions of their engagement with the project were sought. The vast majority of students $(90.5 \%)$ "agreed" or "strongly agreed" that they had achieved more by working in a group rather than alone, and (90.5\%) "agreed" or "strongly agreed" that they had fully engaged with the project, suggesting that these students were still fully invested in the projects. When asked about the positive aspects of group projects, team-work was most commonly cited as a beneficial outcome, closely followed by shared workload, improvement in practical skills, a larger pool of chemistry knowledge available, support from other team members and more opinions available when problemsolving. Comments included: "the workload is shared and team members' differing views, suggestions and knowledge helped with progress and understanding", "[it was] good to collaborate work to move forward more efficiently" and "when [I was] struggling there was a team mate doing a similar reaction to help". However, 25\% of participants "agreed" or "strongly agreed" that other team members did not pull their weight within the group.

\section{Phase 3 - Post-project reflections}

After submission of all assessments, students were again asked their opinions about the use of group projects rather than individual projects. It should be noted that in spring 2018 there was strike action at the university, which likely negatively impacted upon students' overall satisfaction with the projects. This had particular influence during the write-up period. The length of report that students submitted, and the quantity of results produced, were comparable between 2016/17 and 2017/18. As stated earlier, this was reflected in the grades achieved; there were no significant differences in grade outcomes between 2016/17 and 2017/18.

In 2016/17, $44 \%$ of students felt "strongly positive" or "positive" towards their experiences of the group projects overall but preparation of the group report was cited as a negative experience. Issues were ascribed to social loafing and differing opinions regarding time management relating to the submission deadline; some students wanted to complete the report far in advance of the deadline whereas others had a more last-minute approach. One student quoted "[a major problem was] creative differences with others when writing and presenting the project" and "other members of the group did little to no work that contributed the project write-up". In the second iteration of group projects in $2017 / 18,64 \%$ of students felt "strongly positive" or "positive" towards their experiences of group projects overall. This positive change in attitude is attributed to the amendments that were made to the procedure for report preparation and assessment, which will be discussed later. We believe that without the strike action, this percentage would have been significantly higher. Despite the overall improvement in student perceptions of the projects (even with strike action), students still cited social loafing and team-member coasting as negative aspects. In addition, variable or insufficient input from the supervisor was also seen as a negative issue. 


\begin{tabular}{|l|c|c|c|}
\hline \multirow{4}{*}{ Skills } & $\begin{array}{r}\text { Self-identified skills developed } \\
\text { Phase 1, } \boldsymbol{n}=54 \text {; Phase 3, } \boldsymbol{n}=39)\end{array}$ & Change \\
\hline Analytical skills & 4.1 & Phase 3 (\%) & -4.1 \\
\hline Communication & 10.7 & 0 & -0.8 \\
\hline Diplomacy & 1.7 & 9.9 & 8.2 \\
\hline Independence & 4.1 & 9.9 & 1.5 \\
\hline Leadership & 2.5 & 5.6 & 1.7 \\
\hline Organisation & 2.5 & 4.2 & 1.7 \\
\hline Practical Work & 11.6 & 4.2 & -7.4 \\
\hline Presentation skills & 4.1 & 4.2 & 0.1 \\
\hline Report writing & 6.6 & 4.2 & -2.4 \\
\hline Research skills & 5.8 & 4.2 & 5.5 \\
\hline Team-work & 27.3 & 11.3 & -0.3 \\
\hline
\end{tabular}

Table 1 Phase 1 and Phase 3 "What skills do you think that you will develop/have developed, during this work?"

\section{Problems students encountered}

When students were asked about problems that they might face during the group-based project work in Phase 1, responses could be broadly split into two categories, i.e. intrinsic pressures, and extrinsic pressures. Intrinsic pressures were mainly related to timemanagement and workload rather than worries about undertaking the research project itself. Extrinsic pressures revolved around team dynamic and working with others; issues that they had encountered when working in groups previously. Despite these worries, during Phase 1 the vast majority of students $(76.5 \%)$ were in favour of completing project work in a group and because students had completed numerous group-work tasks in the preceding two years of their studies they were able to anticipate any potential issues. Importantly, they also knew how to mitigate them.

In Phases 2 and 3, the negative aspects related to the dynamics of working within a team were often cited, for example personality clashes, social loafing, time management issues, issues with the supervisor and reliance on others for contributions. Quotes included "team members can be hard to organise sometimes, or people may not want to do the work together", "[it was] difficult finding a time when all [team members] are free" and "[I] have to rely on others to being as committed to the project". However, students were still positive overall about their experiences. It should be noted that the Phase 3 data collection point occurred just after the majority of project assessment had taken place. We believe that some of the negative aspects of group-work were mitigated by peer assessment that was used to adjust students' overall final grades (Sharp, 2006). Students were broadly in favour of the use of peer assessment $(87 \%$ in favour; $n=38$ ) as a tool for rewarding input and penalising free-riders.

\section{Skills development}

In Phases 1 and 3, students were asked to identify the skills they thought they would develop, or had developed, during the project. The results from these questions are given in Table 1. In Phase 1, 27.3\% of participants students identified "team-working" as the skill that they would develop the most during the research project. This was closely followed by practical work (11.6\%) and communication skills $(10.7 \%)$. Other skills that may be associated with team-work, for example leadership and diplomacy were only cited by $2.5 \%$ and $1.7 \%$ students, respectively. Students were vague or uncertain of later skills they may develop, such as report writing $(6.6 \%)$, research skills $(5.8 \%)$, presentation skills $(4.1 \%)$, independence $(4.1 \%)$, time management $(4.1 \%)$ and problem solving $(3.3 \%)$.

In Phase 3, team-work was still the most prolific self-identified skill $(27 \%)$, and research skills $(11.3 \%)$, communication skills $(9.9 \%)$ and diplomacy $(9.9 \%)$ the next most regularly 
identified. Interestingly, the change in students self-identifying practical work as a skill developed had declined by $7.4 \%$ between Phase 1 and Phase 3. No students identified having developed analytical skills in Phase 3, and worryingly there was a $2.4 \%$ decline in students self-identifying report-writing skills as being improved, which is contrary to our expectations as the report represents a substantial part of the overall assessment.

At the end of Phase 3, all students agreed that completing project work within a group had a positive impact upon their future career options. They were aware that in future employment they would be likely to be working within a team, or may be asked about their experiences of team-work as part of an interview process.

\section{Conclusions and}

\section{Recommendations}

In conclusion, the implementation of groupprojects into the final year of our BSc programmes was successful and students were satisfied with the outcomes. Students were broadly in favour of working as part of a team in their final year project both before the project started and after all assessment was completed. Reasons for this positive outlook included the support of team-members, the generation of more ideas, and that students could learn from each other. In general, students believed that they had achieved more by working in a group rather than working alone because they were able to work together to collect data and felt like they were contributing to original research. Students also realised that working in a team could be beneficial when looking for employment, and could provide a discussion point in job interviews. The negative aspects of working within a team were mainly related to issues with social loafing. However, they anticipated these issues and were willing to work around them.

Generally, students felt most positive about group projects before the projects started and upon completion of the practical work, but some negativity was seen after students had submitted their final reports. In 2016/17 this was clearly related to the design of the assessment, whereas in 2017/18 this was likely related to the perceived lack of support during the assessment and external circumstances due to industrial action. Amending the assessment task to an individual report rather than a group report was seen as a positive outcome, and is strongly recommended. It should also be noted that the supervisor has a large impact upon student perceptions, particularly in the later stages of the year when students are completing their assessment. It is recommended that supervisors provide strong leadership and guidance for students and are able to provide support where necessary, particularly in relation to writing the report. We recommend allowing students to undertake peer assessment of others' performance.

Finally, throughout the project students believed that the main skill that they developed was team work and that team-working skills would have a positive impact when looking for employment upon graduation. Concerningly, however, students did not perceive that their report writing skills had improved. We recommend that students are provided with additional opportunities to seek help with the report-writing process.

\section{References}

Barrows, H.S. (1986). A taxonomy of problembased learning methods. Medical Education, 20, 481-486. DOI: 10.1111/j.13652923.1986.tb01386.x

Boud, D., \& Feletti, G. (1997). The challenge of Problem-Based learning. London, UK: Kogan Page

Brubacher, M., Payne, R. \& Rickett, K. (Eds.) (1990). Perspectives on small group learning: Theory and practice. Oakvale, Ontario: Rubicon.

Burke, A. (2011). Group Work: How to Use Groups Effectively. The Journal of Effective Teaching, 11, 87-95.

Cabrera, A.F., Crissman, J.L., Bernal, E.M., Nora, A., Terenzini, P.T. \& Pascarella, E.T. (2002). Collaborative learning: Its impact on college students' development and diversity. Journal of College Student Development, 43, 20-34. 
Cohen, E.G. (1994). Restructuring the Classroom: Conditions for Productive Small Groups. Review of Educational Research, 64, 1-35. DOI: $10.2307 / 1170744$

https://www.jstor.org/stable/1170744.

Cranwell, P.B., Page, E.M. \& Squires, A.M. (2017). Assessing Final-Year Practical Work Through Group Projects. Practice and Evidence of Scholarship of Teaching and Learning in Higher Education, 12, 494-504.

Davidson, N. (1994, 2002). Cooperative and collaborative learning: An integrative perspective. In J. Thousand, R. Villa, \& A. Nevin (Eds.), Creativity and collaborative learning: A practical guide for empowering teachers and students (pp. 13-30). Baltimore, MD: Brookes.

Davidson, N. \& Major, C.H. (2014). Boundary Crossings: Cooperative Learning, Collaborative Learning, and Problem-Based Learning. Journal on Excellence in College Teaching, 25, 7-55.

Davidson, N. \& Worsham, T. (1992), Enhancing Thinking Through Cooperative Learning. Teachers College Press.

Laal, M. \& Laal, M. (2012), Collaborative learning: what is it?. Procedia - Social and Behavioural Sciences 31 (2012) 491-495.

DOI: 10.1016/j.sbspro.2011.12.092
Major, C. H., \& Eck, J. C. (2000). Connecting goals, methods, and measures: A problem for problem-based learning. Assessment Update, 12(1), 1-2, 10-11.

Matthews, R.S. (1996), Collaborative Learning: creating knowledge with students, in Menges, M., Weimer, M. and Associates (Eds.). Teaching on solid ground: Using scholarship to improve practice, pp 101-124. San Francisco: Jossey-Bass.

Sharp, S. (2006). Deriving individual student marks from a tutor's assessment of group work. Assessment \& Evaluation in Higher Education, 31, 329-343. DOI: $10.1080 / 02602930500352956$

Springer, L., Stanne, M.E. \& Donovan, S.S. (1999). Effects of Small-Group Learning on Undergraduates in Science, Mathematics, Engineering and Technology: A Meta-Analysis. Review of Educational Research, 69, 21-51. DOI: $10.2307 / 1170643$

Tinto, V., Goodsell, A. \& Russo, P. (1993). Building community. Liberal Education 79, 1621. 